\title{
PORTOFOLIO REKSADANA OPTIMAL SAHAM BLUECHIP PADA KONDISI PASAR SAHAM BEARISH DAN BULLISH
}

\author{
AN OPTIMAL MUTUAL FUNDS PORTFOLIO OF BLUECHIP STOCK ON \\ THE STOCK MARKET CONDITIONS OF BEARISH AND BULLISH
}

\author{
Mohammad Yahya Arief*)1 \\ *) Fakultas Ekonomi, Universitas Abdurachman Saleh Situbondo \\ Jl. PB. Sudirman No.07 Situbondo 68312
}

\begin{abstract}
In bullish and bearish markets, investors should seek the optimization of investments in the mutual funds. This research attempted to elaborate on how to divide funds that are less productive for the investors in accordance with the slogan, "don't pull all of your eggs in one basket"; so that the objective of the return portfolio obtained becomes maximum, and the risk of the return becomes minimum all at once. By the operational and technical study, the data were analyzed by the goal programming model formulation and the simulation of the priorities. The results of the goal programming optimization analysis showed that in bearish market, the investors are risk averse who keep retaining the funds in the form of cash, at least $20 \%$ of cash to maintain the liquidity. As in the bearish market, it is not easy to trade the owned stocks although it is categorized as bluechip stocks. The risk averse investors will also invest the funds at the minimum rate (IDR 20,000,000) on the stock with the lowest return risk, i.e. TLKM stocks. For the risk-seeking investors, they will also optimize the investment of the stocks portfolio with a similar pattern; nonetheless, it is significantly different from the investment into BUMI stocks. The risk-seeking investors invest the funds with the largest proportion of BUMI stocks, while the risk averse investors invest in the smallest proportion. In contrast, in the bullish market, both risk averse and risk seeking investors leave no part of the funds in cash. Both types of investors precisely maximize the investment proportion in BUMI stocks.
\end{abstract}

Keywords: bluechip stocks, bullish markets, bearish market, the goal programming

\begin{abstract}
Abstrak: Pada pasar bullish dan bearish, investor harus mengupayakan optimasi investasinya dalam reksadana. Penelitian ini mencoba menjelaskan bagaimana membagi dana yang kurang produktif bagi investor, sesuai dengan slogan don't pull all of your eggs in one basket; agar tujuan perolehan return portofolio menjadi maksimum dan sekaligus resiko return-nya menjadi minimum. Dengan kajian teknis operasional data dianalisis dengan formulasi model goal programming dan simulasi prioritas kepentingan. Hasil penelitian analisis optimasi goal programming menunjukkan bahwa pada saat pasar bearish, investor risk averter, selayaknya tetap menyisakan dananya dalam bentuk uang kas minimal 20\% untuk menjaga likuiditas, karena pada pasar bearish tidak mudah memperjual-belikan saham yang dimiliki, walaupun saham itu terkatagori bluechip. Investor risk averter ini juga akan menginvestasikan dananya pada tingkat minimal (Rp20 juta) pada saham dengan resiko return terendah, yaitu saham TLKM. Untuk investor risk seeker, juga akan mengoptimalkan investasi portofolio saham dengan pola yang mirip. Namun, berbeda signifikan dalam investasi ke saham BUMI. Investor risk seeker menginvestasikan dana dengan proporsi terbesar pada saham BUMI. Sementara itu, investor risk averter dalam proporsi terkecil. Sebaliknya, pada pasar bullish baik investor risk averter maupun risk seeker tidak menyisakan sebagian dananya dalam bentuk kas. Kedua jenis investor tersebut justru memaksimumkan proporsi investasinya pada saham BUMI.
\end{abstract}

Kata kunci: saham bluechip, pasar bullish, pasar bearish, goal programming

\footnotetext{
${ }^{1}$ Alamat Korespondensi:

Email: yahyaarief99@yahoo.com
} 


\section{PENDAHULUAN}

Investor seringkali kesulitan pada saat akan melakukan investasi, khususnya ketika bunga deposito atau tabungan pada bank mengalami penurunan (Lintner, 2005). Pengembangan produk deposito dan tabungan pensiun dapat dikembangkan dengan strategi pasar dan produk (Ali et al. 2017). Dalam konteks ekonomi individu atau keluarga, menghadapi bunga deposito/ tabungan yang rendah akan memunculkan suatu kreativitas dan keberanian dalam berinvestasi. Selain investasi pada real asset, seperti tanah dan properti, masyarakat harus mencoba produk investasi yang dapat menghasilkan return yang memadai dalam waktu yang singkat. Pandangan ini membuat investasi di sektor finansial mulai berkembang. Slogan berinvestasi "don't pull all of your eggs in one basket", mengindikasikan bahwa dalam berinvestasi dibutuhkan diversifikasi, yaitu sebuah strategi investasi dengan menempatkan dana pada berbagai instrumen investasi yang memiliki tingkat risiko dan potensi keuntungan yang berbeda (Elton et al. 2005). Investor harus membangun suatu portofolio aset, yaitu sekumpulan aset dengan berbagai profil risiko berbeda seperti saham, obligasi, deposito dan lain-lain (Mossin, 2006). Wulandari (2012) dalam penelitiannya menyimpulkan bahwa lebih baik tidak berinvestasi pada reksadana saham dan akan lebih menguntungkan investasi pada investasi bebas risiko. Hal ini dikarenakan berdasarkan risk adjusted performance kinerja reksadana saham negatif selama penelitian.

Reksadana muncul sebagai solusi agar pemodal tidak lagi kesulitan dalam berinvestasi pada sektor finansial. Kesulitan berupa dana terbatas, keterbatasan informasi, kurangnya waktu dan tenaga untuk memonitor portofolio dan risiko-risiko lain dapat diatasi dengan memanfaatkan reksadana. Reksadana adalah bentuk alternatif penanaman modal pada beberapa atau sekumpulan saham. Walaupun reksadana secara fundamental tidak dijamin oleh pemerintah karena tidak termasuk dalam blanket guarantee, namun tetap saja lebih menarik daripada deposito, karena secara struktural mampu menghasilkan keuntungan lebih baik dalam jangk panjang, ditambah dengan faktor pembebasan pajak sebesar final sebesar $20 \%$, khususnya bagi produk reksadana yang berumur kurang dari lima tahun (PP No. 6/2002).
Salah satu produk reksadana adalah reksadana saham, di mana setidaknya $80 \%$ komponen portofolio merupakan investasi saham. Walaupun secara fundamental reksadana tidak dijamin pemerintah (karena tidak termasukdalamprogramblanketguarantee), namuntetap saja lebih menarik daripada deposito, khususnya jika suku bunga perbankan mengalami penurunan (Wiguna, 2008). Beberapa jenis reksadana adalah (a) reksadana pasar uang; (b) reksadana pendapatan tetap; (c) reksadana; dan (d) reksadana campuran. Reksadana saham merupakan reksadana dengan potensi risiko dan return yang paling tinggi dibanding ketiga reksadana lainnya (Sharpe dan William, 2005). Penelitian yang dilakukan Ali et al. (2016) menunjukkan pada tahun 2007, 2008 dan 2009 semua produk reksadana pasar uang memperoleh return yang positif dan negatif. Hal ini menunjukkan bahwa produk reksadana mampu memberikan keuntungan untuk para pemilik reksa dana dana dapat memberikan kerugian dikaremakan reksadana pasar uang masih belum menjadi pilihan investor. Sementara itu, Kaaro (2007) mengatakan penarikan reksadana oleh investor pada tahun 2005 mungkin tidak disebabkan oleh memburuknya kinerja reksadana maupun ketidakkonsistenan kinerja reksadana, melainkan disebabkan oleh kesiapan mental dan kekurangpahaman investor tentang risiko dan return. Selama periode pengamatan (2010-2014) oleh Paranita (2015) tidak ada reksadana saham yang konsisten berkinerja outperform, tetapi hanya ada dua reksadana yang memiliki kinerja terbaik diantara reksadana lainnya karena mampu outperform dari BI Rate dan IHSG selama 4 tahun.

Lestari (2016) membandingkan kinerja reksadana saham konvensional dengan saham syariah menggunakan metode sharper $\mathrm{v} / \mathrm{s}$ yang menunjukkan saham konvensional lebih unggul dibandingkan sebesar 11.900. Berdasarkan uji independent sample $\mathrm{t}$-test terbukti bahwa terdapat perbedaan yang signifikan antara kinerja reksadana saham syariah dengan kinerja reksadana saham konvensional dengan nilai sig 0.012 $>0.05$. Berdasarkan hasil penelitian Waridah dan Mediawati (2016), Reksadana Cipta Syariah Equity merupakan salah satu Reksadana Saham Syariah yang memiliki kinerja paling baik dibandingkan dengan Reksadana Saham Syariah lainnya dan tahun 2012 menjadi tahun kinerja terbaik Reksadana Saham Syariah. 
Portofolio investasi dapat diartikan sebagai tindakan membagi modal pada jenis-jenis investasi tertentu agar risiko return saham menjadi minimal (Markowitz, 2002). Teori portofolio awalnya dikembangkan oleh Markowitz (1952), kemudian dikembangkan Sharpe (1964), Lintner (1965), dan Mossin (1966), yaitu Capital Asset Pricing Model (CPAPM), di mana risiko sistematis saham diukur melalui beta, yaitu tingkat risiko saham yang tidak dapat dihindari. Fama dan French (1992) mengembangkan model baru, yaitu Arbitrage Pricing Theory (APT) yang menjelaskan bahwa risiko return saham tidak hanya dijelaskan oleh beta saja, tetapi banyak faktor yang mempengaruhi hubungan risiko dan return saham.

Pardosi dan Wijayanto (2015) menyimpulkan hasil penelitiannya bahwa investor tidak mempertimbangkan metode Markowitz dalam melakukan perhitungan portofolio. Tidak terdapat perbedaan risiko saham kandidat portofolio optimal metode Markowitz dengan risiko saham bukan kandidat portofolio optimal. Hal ini menunjukkan bahwa preferensi investor yang terdiri dari risk taker dan risk averse tidak mempertimbangkan perhitungan kurva indeferen dalam memilih portofolio optimal.

Ketepatan menganalisis menjadi kunci utama bagi investor untuk mendapatkantingkat return yang diharapkan dari suatu portofolio. Menurut Kewal (2013) Investor yang rasional akan memilih portofolio efisien ini karenamerupakan portofolio yang dibentuk dengan mengoptimalkan satu dari dua dimensi, yaitu return ekspektasi atau risiko portofolio. Oleh karena itu, perlu dianalisa untuk menyusun portofolio yang optimal dan model yang bias diprioritaskan oleh investor. Rahayu (2017) mengatakan ada bias pembingkaian informasi pada investor ketika investor diberi informasi dividen dengan bingkai positif pada saat kondisi pasar bullish dan bias gain domain terjadi ketika investor diberi informasi dengan bingkai positif pada kondisi pasar bullish. Tujuan penelitian ini adalah menyusun portofolio investasi saham yang optimal dan memilih model portofolio terbaik melalui simulasi dan pengujian terhadap berbagai pengaturan prioritas kepentingan investor. Lingkup penelitian ini terbatas pada saham-saham bluechip pada triwulan IV tahun 2017 dari BEI terdiri dari 1) BBRI, (2) TLKM, (3) SMGR, (4) BUMI, dan (5) LSIP.

\section{METODE PENELITIAN}

Penelitian ini merupakan kajian teknis operasional, yang bertujuan menentukan portofolio optimal terhadap saham-saham bluechip (LQ45) pada saat penelitian di lakukan (triwulan IV Tahun 2017). Saham-saham bluechip tersebut adalah: (1) BBRI, (2) TLKM, (3) SMGR, (4) BUMI, dan (5) LSIP. Data yang dianalisis diunduh dari BEI (http://www.idx.co.id/iundex En.html).

Analisis terbagimenjadidua tahap,yaituformulasimodel goal programming, dan tahap iterasi dengansimulasi prioritas kepentingan. Simulasi dilakukan dengan membandingkan keempat model (Model-1 dengan Model-2, dan Model-3 dengan Model-4). Sementara itu, empat model goal programming berdasar kondisi pasar dan prioritas kepentingan investor, yaitu sebagai berikut: (1) Model-1, model pada pasar bullish, dengan prioritas tujuan-1 risiko return portofoliominimum, dan prioritas tujuan-2 return portofolio maksimum; (2) Model-2, model pada pasar bullishdengan prioritas tujuan-1 return portofolio maksimum, dan prioritas tujuan-2 risiko return minimum; (3) Model-3, model pada pasar bearish dengan prioritas tujuan-1 risiko return portofolio minimum, dan prioritas tujuan-2 return portofolio maksiumum; (4) Model-4, model pada pasar bearishdengan prioritas tujuan-1 returnportofolio maksimum, dan prioritas tujuan-2 risiko return portofolio minimum. Secara umum formulasi model GP diekspresikan sebagai berikut :

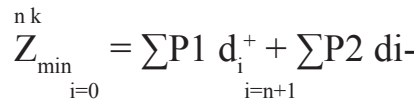

- Kendala risiko return saham: $\sum \beta \mathrm{i}+\mathrm{d}_{1}{ }^{-}-\mathrm{d}_{1}{ }^{+}<2 \beta_{\mathrm{m}}$ (risiko return saham maksimal 2 kali risiko return pasar).

- Kendala pertumbuhan nilai aktiva bersih:

$\sum \mathrm{NAB}_{\mathrm{i}} \mathrm{X}_{\mathrm{i}}+\mathrm{d}_{2}^{-}-\mathrm{d}_{2}^{+}>1,20 \mathrm{TF}$

(pertumbuhan NAB minimal 20\% per tahun)

- Kendala kas minimum:

$\mathrm{TF}-\sum \mathrm{P}_{\mathrm{i}} \mathrm{X}_{\mathrm{i}}+\mathrm{d}_{3}^{-}-\mathrm{d}_{3}^{+}<0,20 \mathrm{TF}$

(kas minimum harus terjaga $20 \%$ dari total dana)

- Kendala investasi pada saham dengan risiko return: $\mathrm{X}_{\mathrm{i}, \beta}>0,20 \mathrm{TF}$ (risiko return tertinggi, minimal 20\% dari total dana pada pasar bullish)

$\mathrm{X}_{\mathrm{i}, \beta}<0,20 \mathrm{TF}$ (risiko return terendah, maksimal 20\% dari total dana pada pasar bearish) 
- Kendala biaya transaksi: $\sum \mathrm{c}_{\mathrm{i}} \mathrm{X}_{\mathrm{i}}+\mathrm{d}_{4}^{-}-\mathrm{d}_{4}^{+}<170.000$ (biaya transaksi untuk setiap saham maksimum sebesar $0,17 \%$ dari total dana yang siap diinvestasikan, diasumsikan sebesar Rp100 juta).

Keterangan: TF (total dana); $\beta_{\mathrm{i}}$ (risiko return saham ke-i); $\beta_{\mathrm{m}}$ (risiko return pasar); NAB (nilai aktiva bersih); $c_{i}$ (biaya transaksi pembelian saham ke-i); $d_{i}^{-}$ (penyimpangan di bawah target keinginan investor); $\mathrm{d}_{\mathrm{i}}^{+}$ (penyimpangan di atas target keinginan investor); $\mathrm{P}_{\mathrm{i}}$ (prioritas kepetingan ke-i).

Secara konseptual, optimasi portofolio saham pada pasar meningkat (bullish) dan pasar menurun (bearish). Optimasi portofolio didekati dengan Goal Programming dengan tujuan meminimumkan penyimpangan-penyimpangan yang tidak dikehendaki investor. Kehendak investor didasari oleh keinginan pribadi, dengan juga mempertimbangkan konvensi yang berlaku di pasar saham, seperti: banyaknya investasi pada saham sesuai kondisi pasar (bullish/bearish); dan teori-teori portofolio, seperti risiko saham ( $\beta$ i), risiko pasar $(\beta \mathrm{m})$, pertumbuhan nilai aktiva bersih, serta jumlah kas minimal yang dipertahankan untuk menjaga likuiditas. Kerangka penelitian optimasi portofolio saham selengkapnya dapat dilihat pada Gambar 1.

\section{HASIL}

\section{Statistik Deskriptif}

\section{Closing Price Saham dan IHSG}

Perbandingan closing price ke lima saham blue chip disarikan pada Tabel 1.Rata-rata closing price dan ratarata IHSG dihitung dengan rata-rata aritmatika, yaitu: $\mathrm{Xbar}=\sum \mathrm{Xi} / \mathrm{n}$. Secara grafis, perbandingan parameter ke lima saham blue chip seperti pada Gambar 2. Tampak saham TLKM merupakan saham dengan rata-rata closing price tertinggi, diikuti saham LISP, saham BBRI, saham SMGR dan saham BUMI. Ratarata closing price ke lima saham blue chip jauh berada di atas IHSG. Ini mengindikasikan bahwa pilihan ke lima saham blue chip yang diamati terkatagori sebagai keputusan pilihan yang tepat, namun belum sampai pada penentuan komposisinya agar portofolio tersebut optimal.

\section{Perhitungan Risiko Return Saham dan Risiko Pasar}

$\beta \mathrm{i}$ dan $\beta \mathrm{m}$ dihitung dengan analisis regresi terhadap gerakan closing price selama hari perdagangan saham yang diamati (Markowitz, 2002). Hasil analisis regresi memperlihatkan bahwa: $\beta$ BBRI $=1,72 ; \beta$ TLKM $=$ 0,$72 ; \beta$ SMGR $=0,84 ; \beta$ BUMI $=2,92 ;$ dan $\beta$ LSIP $=1,13$. Risiko pasar $(\beta \mathrm{m})=0,22$; dihitung dengan menggunakan data poolreturn ke lima saham LQ45 yang bersangkutan. Perbandingan tingkat risiko saham dapat digambarkan pada Tabel 2. Dalam bentuk grafik, tampak seperti Gambar 3. Bi tertinggi adalah saham BUMI $=2,92$ dan terendah adalah saham TLKM $=$ 0,72 . Kelima saham memiliki $\beta i>\beta m(0,22)$. Saham TLKM empat kali lebih rendah dari saham BUMI. Sementara dibandingkan dengan saham SMGR risiko return saham tiga kali lebih rendah dari saham BUMI.

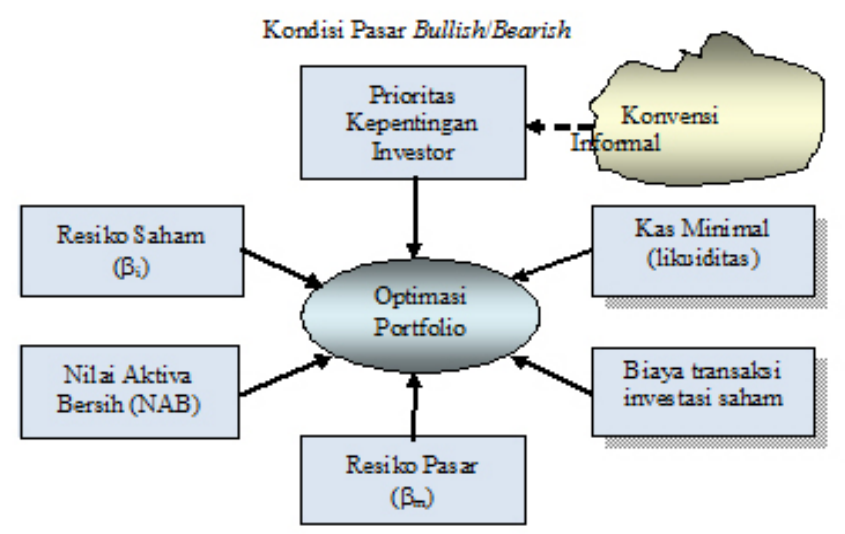

Gambar 1. Kerangka pemikirian penelitian

Tabel 1. Statistik deskriptif rata-rata closing price dan IHSG periode hari perdagangan 30 Oktober 30 Desember 2017.

\begin{tabular}{ccc}
\hline Emiten saham & Rata-rata closing price & IHSG BEI \\
\hline BBRI & $5.956,00$ & $2.078,63$ \\
TLKM & $7.996,00$ & $2.078,63$ \\
SMGR & $4.814,00$ & $2.078,63$ \\
BUMI & $3.688,00$ & $2.078,63$ \\
LISP & $6.876,00$ & $2.078,63$ \\
\hline
\end{tabular}




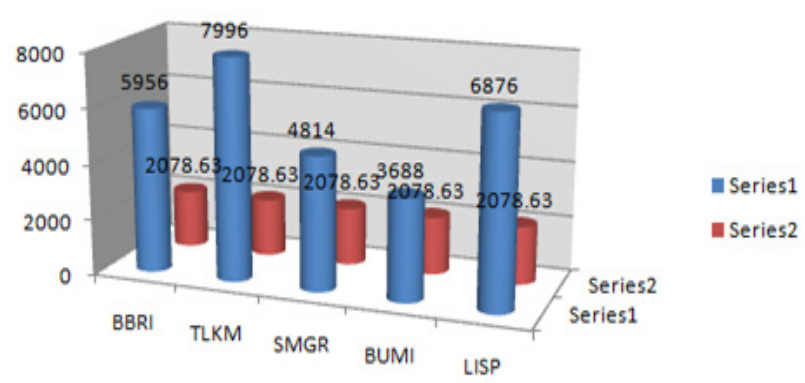

Gambar 2. Rata-rata closing price Saham dan IHSG

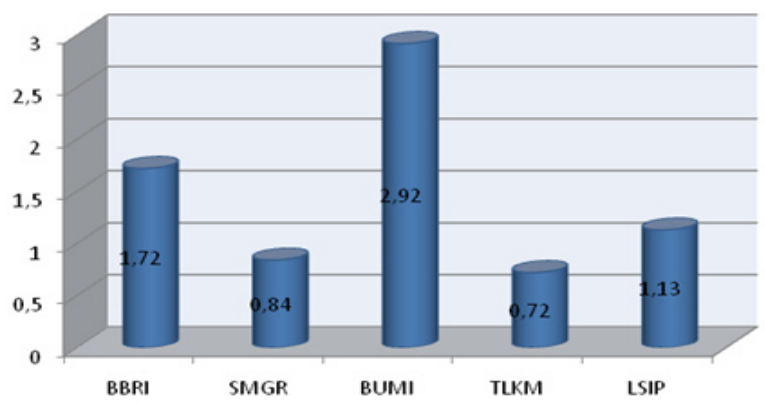

Gambar 3. Resiko return saham LQ45 yang diamati

Tabel 2. Statistik deskriptif resiko return saham dan resiko pasar periode hari perdagangan 30 Oktober - 30 Desember 2017

\begin{tabular}{ccc}
\hline Emiten Saham & $\begin{array}{c}\text { Resiko Return } \\
\text { Saham }(\beta \mathrm{i})\end{array}$ & $\begin{array}{c}\text { Resiko Return } \\
\text { Pasar }(\beta \mathrm{m})\end{array}$ \\
\hline BBRI & 1,72 & 0,22 \\
TLKM & 0,72 & 0,22 \\
SMGR & 0,84 & 0,22 \\
BUMI & 2,92 & 0,22 \\
LISP & 1,33 & 0,22 \\
\hline
\end{tabular}

\section{Analisis Goal Programming}

Model-1: model pada pasar bullish, berlaku untuk investor risk averterdengan prioritas tujuan-1 risiko return minimum, dan prioritas tujuan-2 return portofolio maksimum. Hasil optimasi dengan Solver-Excel seperti pada Tabel 3. Tujuan dengan prioritas-6, yaitu minimum kas yang harus ada untuk menjaga likuiditas tidak tercapai. Tujuan prioritas-5 (pada pasar bullish investasi dalam saham dengan risiko return tertinggi (BUMI) minimal dua puluh juta rupiah tercapai.

Model-2: model pada pasar bullish, berlaku untuk investor risk seekerdengan prioritas tujuan-1 return maksimum, dan prioritas tujuan-2 risiko return minimum. Hasil optimasi dengan Solver-Excel seperti pada Tabel 3. Tujuan dengan prioritas-6, yaitu minimum kas yang harus ada untuk menjaga likuiditas juga tidak tercapai. Prioritas tujuan-5 (investasi di saham BUMI) telah melebihi tingkat minimalnya.

Model-3: model pada pasar bearish, berlaku untuk investor risk averterdengan prioritas tujuan-1 risiko return minimum, dan prioritas tujuan-2 return maksimum. Hasil optimasi dengan Solver-Excel seperti pada Tabel 3. Tujuan dengan prioritas-6, yaitu minimum kas yang harus ada untuk menjaga likuiditas, tercapai. Prioritas tujuan-5, yaitu berinvetasi pada saham dengan risiko return terendah (TLKM), juga tercapai pada titik minimal.

Model-4: model pada pasar bearish, berlaku untuk investor risk seekerdengan prioritas tujuan-1 return saham maksimum, dan prioritas tujuan-2 risiko return minimum. Hasil optimasi dengan Solver-Excel seperti pada Tabel 3. Tujuan dengan prioritas-6, yaitu minimum kas yang harus ada untuk menjaga likuiditas, tercapai. Prioritas tujuan-5, yaitu berinvetasi pada saham dengan risiko return terendah (TLKM), juga tercapai pada titik minimal; ini tidak melanggar konvensi informal para investor pada pasar bearish. Investasi saham BBRI tidak lagi memiliki komposisi tertinggi jika dibanding dengan komposisi pada pasar bullish. Investasi saham BUMI menjadi tertinggi, jauh lebih tinggi jika dibanding pada pasar bullish.

\section{Perbandingan Hasil Optimal Keempat Model}

Pada saat pasar bullish, tujuan-6, mempertahankan kas minimal Rp20 juta tidak tercapai baik pada Model-1 maupun Model-2. Sikap investor (risk seeker atau risk averter) tidak menghasilkan perbedaan komposisi portofolio optimal secara signifikan; keduanya menghasilkan investasi dalam proporsi besar untuk saham SMGR dan BUMI. Konvensi yang berlaku di pasar saham terpenuhi baik untuk Model-1 maupun Model-2 pada pasar bullish, yaitu minimal berinvestasi $20 \%$ pada saham dengan risiko return tertinggi (BUMI). Pada saat pasar bearish, investasi kas maksimal Rp20 juta terpenuhi baik untuk Model-3 maupun Model-4. Investor yang terkatagori risk averter ternyata akan memperkecil investasinya pada saham dengan risiko return tinggi (BUMI), yaitu hanya sekitar Rp8,5 juta; sedang risk seeker justru memaksimumkan investasinya pada saham BUMI (Rp30,98 juta). Situasi ini sangat logis, investor risk seeker berani menghadapi risiko, dengan harapan memperoleh return tinggi (Markowitz, 2002). BBRI tahun 2009 salah satu saham yang paling menguntungkan untuk investor tipe aggressive (Prabowo, 2013). 
Tabel 3. Hasil Optimal Model-1, Model-2, Model-3, dan Model-4

\begin{tabular}{ccccc}
\hline \multirow{2}{*}{ Komponen Portofolio } & \multicolumn{4}{c}{ Nilai Investasi (Rp) } \\
\cline { 2 - 5 } & Model-1 & Model- 2 & Model-3 & Model-4 \\
\hline BBRI & 0,00 & 0,00 & $51.530 .569,01$ & $29.020 .000,00$ \\
TLKM & 0,00 & 0,00 & $20.000 .000,00$ & $20.000 .000,00$ \\
SMGR & $41.877 .560,00$ & $33.877 .551,20$ & 0,00 & 0,00 \\
BUMI & $58.122 .440,00$ & $66.120 .448,80$ & $8.469 .430,99$ & $30.980 .000,00$ \\
LSIP & 0,00 & 0,00 & 0,00 & 0,00 \\
Kas & 0,00 & 0,00 & $20.000 .000,00$ & $20.000 .000,00$ \\
Total Investasi & $100.000 .000,00$ & $100.000 .000,00$ & $100.000 .000,00$ & $100.000 .000,00$ \\
\hline
\end{tabular}

Sementara itu hasil penelitian Prakoso et al. (2018) mengatakan bila investor berinvestasi pada indeks LQ 45 lebih baik memperhatikan BI rate, harga emas, harga minyak, dan nilai kurs tukar sebagai dasar pengambilan keputusan investasi yang dilakukannya. Pada indeks Pefindo 25 investor sebaiknya memperhatikan BI rate, IHK, dan harga minyak sebagai dasar pengambilan keputusan investasi.

\section{Implikasi Manajerial}

Hasil yang telah diperoleh dari penelitian ini dapat dimunculkan implikasi manajerial untuk investor dapat memilih saham bluechip dalam berinvestasi, sebab saham bluechip dengan cepat dapat dijual kembali jika investor membutuhkan dana segar dengan segera dan konvensi informal yang berlaku pada pasar saham bullish atau bearish memang patut dipertimbangkan, agar risikonya bisa ditekan.

\section{KESIMPULAN DAN SARAN}

\section{Kesimpulan}

Pada pasar bullish, portofolio optimal bagi investor risk averter. Tidak terjadi pelanggaran terhadap konvensi informal yang dianut para investor, kecuali konvensi kas minimal untuk menjaga likuiditas operasional. Pada pasar yang sama bagi investor risk seeker, juga tidak terjadi pelanggaran terhadap konvensi informal. Bagi kedua jenis investor, pada pasar bullish, saham SMGR dan saham BUMI merupakan saham potensial. Pada pasar bearish, portofolio optimal bagi investor risk averter. Bagi kedua jenis investor, dua saham, yaitu SMGR dan LISP tidak dimasukkan ke dalam portofolio, namun kas minimum tetap dipertimbangkan. Dengan demikian dapat dinyatakan bahwa pasar sedang bearish, tiga saham, yaitu BBRI, TLKM dan BUMI merupakan saham potensial untuk dipilih sebagai komponen portofolio.

Hasil simulasi yang dilakukan dengan variasi setting prioritas tujuan, ternyata tidak menimbulkan perbedaan portofolio optimal secara signifikan dibanding portofolio awal. Dengan demikian, dapat dinyatakan bahwa perubahan prioritas tujuan tidak berdampak terhadap proporsi saham dalam portofolio optimal. Hal ini sesuai dengan pernyataan Gladish et al. (2005).

\section{Saran}

Rekomendasi berdasar temuan dalam penelitian ini adalah model yang dianalisis pada penelitian ini menggunakan asumsi bahwa total dana yang disiapkan untuk membeli reksadana sebesar Rp100 juta hanya sekedar untuk memberi gambaran yang sederhana dan mudah dipahami. Agar model-model dapat berlaku umum maka praktisi dapat menggunakan angka persentase. Dengan demikian, berapapun ketersediaan dana tidak menjadi masalah dalam memformulasikan modelnya.

\section{DAFTAR PUSTAKA}

Ali S, Baga LM, Sanim B. 2017. Strategi pengembangan portofolio produk investasi bank ABC. Jurnal Aplikasi Bisnis dan Manajemen (JABM), 3(3): 427-434. http://dx.doi.org/10.17358/ jabm.3.3.427

Elton JE, Martin JG. 2005. Modern Portfolio Theory and Investment Analysis. New York: John Wiley and Sons Inc.

Fama EF, French KR. 1992. The cross section of expected stock return. Journal of Finance 47(2):427-465. https://doi.org/10.1111/j.15406261.1992.tb04398.x. 
Kaaro H. 2007. Analisis kinerja reksadana saham di Indonesia. Jurnal Manajemen \& Bisnis 6(2):138148. https://doi.org/10.24123/jmb.v6i2.109.

Kewal SS. 2013. Pembentukan portofolio optimal saham-saham pada periode bullish di Bursa Efek Indonesia. Jurnal Economia 9(1): 81-91.

Lestari WR. 2016. Kinerja Reksadana Saham Syariah dan Reksadana Saham Konvensional. Jurnal Manajemen Magister Darmajaya 1(1): 116128.

Lintner J. 2005 Security prices, risk and maximal gains from diversification. Journal of Finance 47:1337.

Markowitz HM. 2002. Portfolio selection. Journal of Finance 7:77-91. https://doi.org/10.1111/j.15406261.1952.tb01525.x.

Mossin J. 2006. Equilibrium in a capital asset market. Econometrica, Journal of Finance 34:768-783. https://doi.org/10.2307/1910098.

Paranita C. 2015. Analisis kinerja investasi dalam reksadana saham (equity funds) dengan metode sharpe dan treynor. Jurnal Administrasi Bisnis 27(1):1-7.

Pardosi B, Wijayanto A. 2015. Analisis perbedaan return dan risiko saham portofolio optimal dengan bukan portofolio optimal. Management Analysis Journal 4(1):1-9. https://doi.org/10.15294/maj. v4i1.7210.

Prabowo H. 2013. Analisis portofolio saham dengan metode capm dan markowitz. Binus Business Review 4(1):360-369. https://doi.org/10.21512/ bbr.v4i1.1126.

Prakoso D, Firdaus M, Andati T. 2018. Pengaruh variabel makroekonomi terhadap return indeks LQ 45 dan Pefindo 25. Jurnal Aplikasi Bisnis Dan Manajemen (JABM) 4(3):387. http://dx.doi. org/10.17358/jabm.4.3.387.

Rahayu CWE. 2017. The influence of information framing towards investors reaction in bullish and bearish market condition: an experiment. Jurnal Dinamika Manajemen 8(2):199-207. https://doi. org/10.15294/jdm.v8i2.12760.

Sharpe, William F. 2004. Capital asset prices: a theory of market equilibrium under risk condition. Journal of Finance 19(3): 442-453. https://doi. org/10.1111/j.1540-6261.1964.tb02865.x.

Waridah W, Mediawati E. 2016. Analisis kinerja reksadana syariah. Jurnal Riset Akuntansi dan Keuangan 4(2):1077-1086. https://doi. org/10.17509/jrak.v4i2.4043.

Wulandari PA. 2013. Evaluasi kinerja reksadana saham Indonesia periode 2007-2011. Jurnal INTEKNA: Informasi Teknik dan Niaga 13(3): 227-234. 